\title{
A definition for gamification: anchoring gamification in the service marketing literature
}

\author{
Kai Huotari ${ }^{1,2}$ (D) Juho Hamari ${ }^{3}$
}

Received: 1 May 2014 / Accepted: 17 December 2015 /Published online: 15 January 2016

(C) Institute of Information Management, University of St. Gallen 2016

\begin{abstract}
Gamification" has gained considerable scholarly and practitioner attention; however, the discussion in academia has been largely confined to the human-computer interaction and game studies domains. Since gamification is often used in service design, it is important that the concept be brought in line with the service literature. So far, though, there has been a dearth of such literature. This article is an attempt to tie in gamification with service marketing theory, which conceptualizes the consumer as a co-producer of the service. It presents games as service systems composed of operant and operand resources. It proposes a definition for gamification, one that emphasizes its experiential nature. The definition highlights four important aspects of gamification: affordances, psychological mediators, goals of gamification and the context of gamification. Using the definition the article identifies four possible gamifying actors and examines gamification as communicative staging of the service environment.
\end{abstract}

Responsible Editor: Artur Lugmayr

Kai Huotari

kai.huotari@culturel.com

Juho Hamari

juho.hamari@uta.fi

1 Pohjoinen Rautatiekatu 15 B 11, 00100 Helsinki, Finland

2 Helsinki Institute for Information Technology HIIT and Centre for Relationship Marketing and Service Management CERS, Hanken School of Economics/CERS, Arkadiankatu 22, P.O. Box 478, FIN-00101 Helsinki, Finland

3 Game Research Lab, School of Information Sciences, University of Tampere,

FIN-33014 Tampere, Finland
Keywords Gamification · Game design · Service marketing · Service design $\cdot$ Persuasive technologies $\cdot$ Service-dominant logic

JEL Classification M3 - Marketing and Advertising . M31 - Marketing

\section{Introduction}

Gamification has raised significant interest both in industry (Kim 2008) and increasingly in academia (see Hamari et al. 2014a; Hamari et al. 2014b for reviews) in the last few years. However, this discussion has remained primarily in the realm of game studies and human-computer interaction (HCI). Although games are offered in increasing numbers as services to consumers, very few academic articles have been published that bridge game studies and the service or marketing literature (e.g., Hamari and Järvinen 2011; Hamari and Lehdonvirta 2010; Hamari et al. 2015; Sigala 2015; Stenros and Sotamaa 2009). Anchoring findings from game studies in the existing service marketing literature could provide a framework in which game play can be viewed as a part of the overall service and for understanding how it supports the core service offering.

Electronic commerce and electronic markets are one of the main areas where service marketing and technology intertwine. According to Alt et al. 2010, service-oriented solutions can bring many benefits to electronic commerce and technology in several areas such as healthcare (see e.g. Cocosila and Archer 2010), telecommunication (see e.g. Czarnecki et al. 2010), logistics, education and others. While gamification has become one of the most popular trends of electronic markets and commerce, understanding it from the service marketing perspective could bring proven models 
from service marketing to the development of "gamified" services. Currently, gamification has already been employed and researched in majority of the above mentioned domains such as commerce (Bittner and Shipper 2014; Cechanowicz et al. 2013; Hamari 2013; Hamari 2015; Terlutter and Capella 2013), education (Denny 2013, Hakulinen et al. 2013; Domínguez et al. 2013; de-Marcos et al. 2014; Farzan and Brusilovsky 2011; Simões et al. 2013; Christy and Fox 2014; Filsecker and Hickey 2014; Bonde et al. 2014), healthcare (Jones et al. 2014; Hamari and Koivisto 2015), and logistics (Hense et al. 2014; Klemke et al. 2014). However, even though empirical research is accumulating on the deployment of gamification in several areas, we have still had a gap in our conceptual understanding about what gamification is and how it can be defined. This further hinders our efforts in employing and investigating gamification in a consistent manner. In the next section of the paper, we give an overview of the central concepts of gamification in game studies. The third section introduces service marketing, an emerging approach to marketing in general, before we present some of its concepts that are relevant for the present study. In Section 5, we situate games relative to the service marketing literature; then, in Section 6, we elaborate on the experiential nature of games. We go on to present a definition for gamification from the service marketing perspective (Section 7) and show how it can be used for identification of four possible gamification providers (Section 8). Section 9 discusses how gamification can be viewed as communicative staging of service environment. The paper concludes with a summary of the results, discussion of their contribution both to the scientific community and for practitioners, and some directions for future research.

\section{Games and gamification from a game studies perspective}

In game studies, games have been defined in terms of a set of necessary conditions. None of these numerous conditions suffices in itself to characterize a game, and it is only in their combination that a game emerges (Juul 2003; see also Deterding et al. 2011 on gamification). Juul surveyed seven existing definitions, analysing them before offering a new definition. In the definitions Juul compiled, the conditions necessary for games vary. For example, Avedon and SuttonSmith (1971) describe a game as an "exercise of voluntary control systems in which there is an opposition between forces, confined by a procedure and rules in order to produce a disequilibrial outcome." A more recent work (Salen and Zimmerman 2004, p. 96) defines a game in the following way: "A system in which players engage in an artificial conflict, defined by rules that result in a quantifiable outcome." Juul (2003, p. 35) describes a game as "a rule-based formal system with a variable and quantifiable outcome, where different outcomes are assigned different values, the player exerts effort in order to influence the outcome, the player feels attached to the outcome, and the consequences of the activity are optional and negotiable." Although the definitions vary in emphasis, they all feature both a systemic component, referring to how the game is constructed, and an experiential component, describing the human involvement in the game. In Table 1, below, we have listed the conditions found in previous literature's definitions of games and gamification.

In addition to arranging the conditions by their systemic/ experiential nature, Table 1 groups them into three distinct levels of abstraction. The first level shown, the most abstract, is addressed by all of the definitions. Central here is that games are systems - they are composed of several interacting sets of mechanisms and actors (systemic condition) - and that games always require the active involvement of at least one player (experiential condition). At the second level of abstraction are conditions that are characteristic of games but are not necessarily present in all games. Under this category fall such systemic conditions as rules, conflicting goals, and uncertain outcomes, generally referred to as game design elements. Among level-2 experiential conditions are hedonic experiences, suspense (resulting from players valuing outcomes but being uncertain of them), and flow. Also, the mastery and competence mentioned by Ryan et al. (2006) can be placed in this category. The third level consists of conditions that are unique to games. However, no content is shown in the table for this level - it has not been addressed by previous literature positing definitions of games. In fact, there do not seem to be elements that are unique to games.

The lack of systemic conditions unique to games is not surprising, since Juul (2003) and Deterding et al. (2011) have stated that a game emerges in a combination of conditions and that none of the conditions alone is sufficient for constituting a game. However, it is surprising that none of the definitions describe an experiential condition unique to games. If there were no such condition, how could anyone recognize a game? As Juul and Deterding et al. put the question, how would anyone know when a game has emerged from a combination of various necessary conditions if it were not for an experiential condition unique to games? The term "gamefulness" could be used to describe such a unique condition, just as McGonigal (Takahashi 2011) has suggested. Yet Deterding et al. (2011) draw a distinction between games and gamified services, and they state that both can lead to gameful experiences, thus defining gamefulness as a condition that is not unique to games.

There does not seem to exist a single common articulation for gamefulness or gameful experience, nor is there clear consensus as to which kinds of experiences can arise only from games. As a starting point, however, psychologists and game researchers have suggested, for example, the following as 
Table 1 Game conditions presented in previous literature

\begin{tabular}{|c|c|c|c|c|}
\hline Level of abstraction & Systemic conditions & Basis & Experiential conditions & Basis \\
\hline 1st level (common to all games) & Games as systems & $1,2,3,4,5,6,7,8,9$ & $\begin{array}{l}\text { Requirement of player/user } \\
\text { voluntary involvement }\end{array}$ & $1,2,3,4,5,6,7,8,9$ \\
\hline \multirow{7}{*}{$\begin{array}{l}\text { 2nd level (characteristic of games } \\
\text { but not necessary in all games) }\end{array}$} & \multirow[t]{2}{*}{ Conflicting goals } & \multirow[t]{2}{*}{$1,3,4,6,7,8,9$} & Hedonic pleasure & $2,4,5,6,10,13$ \\
\hline & & & Mastery/achievement & 10,13 \\
\hline & \multirow[t]{2}{*}{ Rules } & \multirow[t]{2}{*}{$1,2,3,4,5,6,7,8,9$} & Relatedness & $10,12,13$ \\
\hline & & & Suspense & 4,6 \\
\hline & \multirow[t]{3}{*}{ Variable and uncertain outcomes } & \multirow[t]{3}{*}{$1,2,4,6,7,8$} & Competence & 10,13 \\
\hline & & & Flow & 11 \\
\hline & & & Immersion & $10,12,13$ \\
\hline 3rd level (unique to games) & - & & - & \\
\hline
\end{tabular}

1 = Avedon and Sutton-Smith (1971), 2 = Caillois (1958), 3 = Crawford (1982), 4 = Deterding et al. (2011), 5 = Huizinga (1944), 6 = Juul (2003), 7 = Kelley (1988), 8 = Salen and Zimmerman (2004), 9 = Suits (1978), 10 = Ryan et al. (2006), 11 = Csíkszentmihályi (1990), 12 = Yee (2006), 13 = Hamari and Tuunanen (2014)

characteristic psychological factors of a "gameful experience": mastery, autonomy, flow, suspense, and so forth (see Table 1). Therefore, instead of explicitly mentioning various psychological factors linked to games, we employ the shorthand "gameful experiences" or "gamefulness." While we recognize that such abstraction is problematic for accurately pinpointing a phenomenon, working out exactly what "gamefulness" means is beyond the scope of this paper, for defining this term would also require us to define games themselves.

The term "gamification" was first used in 2008, in a blog post by Brett Terrill (2008). He describes the word as "taking game mechanics and applying them to other web properties to increase engagement." In 2010, the term entered more widespread use in the industry (Deterding et al. 2011) and in academia (Hamari et al. 2014b).

Regardless of the attention the term quickly gained in the industry, academia has been slow to react. To our knowledge, there are only three peer-reviewed definitions for it: the one stated by Deterding et al. (2011), that presented in an early, brief, and considerably different version of the present work (Author anonymized 2012) and the one by Werbach (2014). Deterding et al. describe gamification as the use of game design elements in non-game contexts. While they do discuss the experiential aspects of games, their definition of gamification adopts only a systemic perspective to games, an approach that we argue has several shortcomings, which we will discuss in Section 6. Werbach (2014), in turn, adopts a designer's point of view and presents a very general definition of gamification as "the process of making activities more game-like", in order to bring academic and practitioner perspectives closer together. However, the vagueness of Werbach's definition makes connecting the concept of "gamification" very hard to other theoretical frameworks. Our attempt, in this article, is to anchor gamification in the growing body of literature on service marketing. This line of marketing research has gained increasing interest also outside the scope of services during the last ten years. Through service marketing theory, any game can be seen as a service, and by defining gamification using this theoretical framework, the term can be connected to any company's larger business strategy. To give context to our arguments, let us first turn to the service marketing literature - its origins and some of its key concepts.

\section{The emergence of the service marketing field}

Marketing science was developed in the 1950's on the basis of the goods-selling logic of the manufacturing industries. The mainstream marketing approach using marketing mix management and the 4P developed around this model where the exchange of physical goods and transactions were in the focal point. As services gained more weight in the economy, scholars grew interested in the marketing of services. Mainstream marketing looked at services as variants of physical products. However from 1970's onwards, a handful of scholars came to the conclusion that the classical marketing axioms could not provide sufficient understanding of services (Grönroos 2007) and began to develop a service marketing theory based on the distinctive characteristics of services.

This new line of service research was developed quite independently of mainstream marketing science until the 1990s (Grönroos 1994). What followed was that marketing theory based on the service paradigm began to seem applicable also for goods marketing. This tendency was strengthened in 2004 when Vargo and Lusch introduced the idea of "service-dominant logic" (S-D logic) for marketing and proclaimed that a service-focused approach should replace classical mainstream marketing theory. Similarly, Grönroos 
(2006) compiled contributions from the Nordic School of Marketing Thought under the label service logic and stated that they can be applied also to goods if the conception of consumption process is widened. According to Grönroos (2006), goods can be considered as resources in a process that actually forms the service.

Vargo et al. (2010) refer to the marketing research of services following the mainstream marketing axioms as "services marketing" (in plural) and to the new approach as "service marketing" (in singular). The plural form of "services marketing" is based on the idea that mainstream marketing sees both goods and services as outputs of production, whereas the singular form of "service marketing" emphasizes that the new service approach considers service as a collaborative process of service providers and customers (Vargo et al. 2010).

In recent years, the service paradigm has gained growing interest in academia (see e.g. Alt et al. 2010; Dai and Salam 2014) as well as in industry due to its generalizability. Two key concepts of "service marketing", those of customer as coproducer and value-in-use, help to explain this universal applicability and the profound difference between the mainstream, goods-dominant logic and the new approach based on service marketing.

Mainstream marketing theory sees the production as carried out by the company, and the value is considered to be created during the production process by the company and embedded in the resulting product. The product then "carries" the value within it, and the value is transferred from company to customer with the transaction for hand-over of the product. In a service context, however, the value-in-exchange approach is rendered meaningless, since there is no physical product to which the value could be attached.

The service marketing literature views the customer as always a co-producer of the service - as participating in a production process wherein the value is generated only once the customer uses the service or goods. In this value-in-use model, the company's role in the value creation is to support the customers' processes by offering resources for them.

Vargo and Lusch's (2004) S-D logic divides these resources into two categories, initially introduced by Constantin and Lusch (1994): operand and operant resources. Both consumers and companies offer operant and operand resources for the valuecreation process. Operand resources are resources acted upon. They are often tangibles, such as goods and raw materials, but monetary possessions and spaces too can be viewed as operand resources (Arnould et al. 1998). Operant resources, in contrast, are employed to act on operand or other operant resources. They produce effects and support human ingenuity. Among operant resources are knowledge, competencies, and intellectual property rights (IPR), yet operant resources encompass social resources too, such as skills requiring physical involvement (e.g., knowing how to play a musical instrument) or a network of friends. Operant resources are always culture-dependent.
In practical operations, the company first deploys its operant resources to mold its operand resources or other operant resources such that it can offer the customer a value proposition (ibid.). A customer who chooses this proposition over others engages in a value creation process to which said customer brings his or her own operant and operand resources. Thereby, the value-in-use is experienced and determined by the beneficiary phenomenologically (Vargo and Lusch 2008).

\section{Service, service systems, and service packages}

Before we can develop a definition of gamification, three key concepts of service marketing need to be defined: service, service system, and service package.

Vargo and Lusch (2004, p. 2) define "service" as "the application of specialized competences (knowledge and skills), through deeds, processes, and performances for the benefit of another entity or the entity itself." Accordingly, any intentional act - no matter how small - that assists an entity can be considered a service.

A systematic bundle of services constitutes a service system. The latter term, according to Vargo and his colleagues (2008, p. 145), refers to "an arrangement of resources (including people, technology, information, etc.) connected to other systems by value propositions." The aim with a service system is utilization of its resources and the resources of others to improve the entity's circumstances and others'. An illustrative example of a service system is Internet shopping that requires cooperation among a Web store provider, money-transfer firm, and shipping company if it is to function. However, any organization, an individual department thereof, or even a family could be viewed as a service system (Spohrer et al. 2008).

The service package model (Grönroos 2007), in turn, helps firms manage bundled services or service systems. The basic service package is composed of the core service, enabling services, and enhancing services. Enabling services are required for consuming of the core service, and enhancing services support the offering of the core service and thus increase its value or differentiate it from competitors' services. In the case of an airline, the core service is transportation. Check-in for a flight would be considered an enabling service, because it is required for the passengers' travel by air, whereas in-flight services such as meals and drinks would be viewed as enhancing services, because they are not mandatory and are utilized only to increase the value of the core service and for differentiation value $v i s-\grave{a}$-vis other airlines.

\section{Games as service systems}

As has been described above, service marketing defines a "service" very broadly and, therefore, virtually any system 
or interactive process with a value-proposition can be considered a service or a service system and be examined through service marketing theory. Furthermore, game literature and service marketing literature complement each other in many ways. Thus, when viewed through the lens of service marketing theory, game design elements can be described as services and games as service systems. This conceptualization is supported by Table 1, which shows that games are always regarded as systems demanding the player's active involvement.

Games are thus co-produced by the game developer and those playing them. The game developer's part of the coproduction commonly takes place first. It requires financing (an operand resource) and game design activities such as designing visuals, inventing a storyline, and building a platform (operant resources). The players' part of the co-production and of the value-creation process is performed each time the game is played or otherwise interacted with. In the playing, the player's skills, previous experience, and knowledge become operant resources of the game. These elements make the game experience unique and subjectively experienced. The core service of the game is provision of hedonic experiences such as a welcome challenge, suspense (Kim 2008), "gamefulness" (McGonigal 2011), and flow (Csíkszentmihályi 1990). These patterns and attributes hold even when the game is developed partly or solely by the player.

\section{Subjective nature of the experienced value of a game}

It is noteworthy that, from the service marketing perspective, it is always the player's participation in the game - i.e., playing the game - that completes the production of the game service. This notion is consistent with the definitions of games presented in Section 2, in all of which the player's voluntary commitment and participation are a key building block of a game. However, service marketing theory holds that the value of a service is determined solely by the customer's subjective experience: service providers do no more than make their offering available. It follows from this that the value of a game service - be it "pleasure," "suspense," "mastery," or "gamefulness" - is always determined by the individual player's subjective perception. In other words, the use of a game service may lead to a gameful experience for one user but not another user. This difference in outcome may arise, for example, from differences in the operant resources of the two users/players, such as skills (e.g., Hamari and Tuunanen 2014; Yee 2006).

Experiences of playing a game and of determining what even is a game are deeply individual. Accordingly, in our view, a game emerges only when the use of the service results in a gameful experience. Therefore, we see gamefulness as an experiential condition unique to games. Here, we diverge sharply from the definition of gamification proposed by Deterding et al. (2011), which stresses that only non-games can be gamified. Then, the obvious question is this: how can a service designer possibly identify a non-game context when the existence of a game is dependent on the player/user's subjective perception? If the sensation of gamefulness is not unique to games, this question becomes impossible even for individual consumers to answer. For example, a stock market and a dashboard for participating in it can readily be perceived by some users as creating gameful experiences though not generally seen as a game by all users. Thinking about what constitutes a "full-fledged game" and what does not can only lead the designer astray from what should be the focus: customer/user/player experience.

These issues and the resulting conundrums led us to seek an alternative way to define gamification from the perspective of service marketing.

\section{A proposed definition for gamification}

On the basis of the literature discussed above, we define gamification in the following way:

Gamification refers to a process of enhancing a service with affordances for gameful experiences in order to support users' overall value creation.

We wish to emphasize that this definition highlights the goal of gamification - the experiences that it attempts to give rise to - rather than the methods. Past definitions have relied on the notion that gamification proceeds from the use of game design elements. However, there does not seem to be a clearly defined set of game elements - i.e., elements that are strictly unique to games yet that do not automatically give rise to gameful experiences. If we subscribe to the idea that game elements create a game or gamify a system, we could conclude that the aforementioned stock exchange dashboard; decision support systems; loyalty programs; and other services featuring, for example, levels, points, and progress metrics would also be games, regardless of the users' subjective experiences. Furthermore, gamification is not always carried out through any particular concrete elements alone. Therefore, we argue that basing definitions of gamification (or games) on a set of mechanics is problematic. Instead, we propose that gamification could be understood more broadly as a process in which the 'gamifier' is attempting to increase the likelihood of the emergence of gameful experiences by imbuing the service with affordances for that purpose (be they badges, points or more implicit cues).

The term affordance has become quite established in the human-computer interactions field and refers to elements that enable activities specific to that affordance in the environment 
in which it occurs (Gibson 1977; Norman 2002; Greeno 1994; Zhang 2008). In general, affordances refer to "actionable properties between an object and an actor" (Gibson 1977). Affordances do not force the user to act upon them or are not necessarily even interpreted by the user in the manner intended by the designer. However, they open the possibility for occurrence of experiences or behaviours. 'Motivational affordances' can be considered as stimuli designed with the intent of provoking the users' motivational needs and affecting the users' psychological states (Zhang 2008; Jung et al. 2010; Huotari and Hamari 2012; Hamari 2013).

The idea of affordances is also highly compatible with the discourse on gamification as it implicitly contains the idea that the users voluntarily interact with the system and its affordances rather than seeing the system elements as something the user 'automatically' has to interact with (Zhang 2008; Jung et al. 2010; Huotari and Hamari 2012). This view is also in line with the theoretical view of service-dominant logic (Vargo and Lusch 2004) where the value of a system or a service emerges from the voluntary user-driven interaction between the user and the system. In this vein, any system can be seen as a set of affordances intended to enable the user to realize the system related goals.

The definition of gamification proposed by Deterding et al. (2011) culminates around the set of game design elements, implying that determining whether a system is gamified is defined based on existence of elements characteristic of games in that system. The definition of gamification proposed herein, on the other hand, centres on the abovementioned 'favourable' motivations and psychological states invoked by the (motivational) affordances. This implies that the focus of gamification is related to the psychological outcomes rather than specifics of design. These psychological outcomes also further act as mediators for behavioural outcomes and value creation of gamification. In other words, the affordances of a system invoke psychological states and emotions (Zhang 2008; Jung et al. 2010; Hamari 2013), which, mediate the behavioural outcomes and value creation. Table 1 outlines psychological states that are commonly encountered in games. Meta-reviews on gamification studies (Hamari et al. 2014a; Hamari et al. 2014b) find that these psychological factors are also commonly investigated in the literature on gamification, although, most empirical studies circumvent the psychological mediators and focus directly on behavioural outcomes (Table 2).

We find it important to highlight also that our definition does not imply that the process of gamification is inherently successful: gamification can only attempt to support the user in creating gameful experiences that promote the user's overall value creation. Nevertheless, the definition specifies two goals that gamification can be measured against: 1) affording gameful experiences and 2) supporting the overall value creation.
If gamification is designed solely to increase certain behaviours instead of focusing on the emerging gameful experiences, the designers are in danger of falling into a trap that leads to conflict between the goal of changing people's behaviour and that of creating valuable experiences. One of the defining elements of gameful experience (see Table 1) is that it is voluntary, autotelic and an intrinsically motivated. If the designer attempts to direct player/customer decision-making in such a way that the player or user's free choice is reduced, the design moves further from what is at the core of a gameful experience (on games and autonomy, see Ryan et al. 2006). Again, however, as we noted above, defining "gamefulness" is, on account of what it entails, beyond the scope of this paper. In the discussion here, we rely on previous theorization that includes, for instance, discussion of flow (Csíkszentmihályi 1990), autonomy, mastery, and general intrinsically motivated experiences as being gameful (see Table 1), as addressed in Section 2.

As for support for the overall value creation, the word "enhancement" in the definition refers to the service package concept from service marketing literature, as introduced in Section 4. It sets the other goal for gamification from a service design perspective: the gameful experiences should support the value-in-use of the core service as experienced by the user. If, for example, gamification is successful in creating gameful experiences but in such a way that they distract the user from using the core service, the gamification cannot be considered successful overall. Therefore, it is important to differentiate among the core service, the enhancing service(s), and their result: the gamified service.

Under the definition given, Foursquare, for example, is not a gamified service in itself, though it possesses potential to gamify (and, thereby, enhance) other services, such as restaurants or bars, through rules, goal-setting, variable outcomes, feedback, and rewards. Moreover, the definition remains agnostic to the nature of the core service. The core service could even be a game that can be further gamified, with the output being so-called meta-games. From this perspective, not only non-games can be gamified.

The process nature of gamification often renders it difficult or even impossible to know whether a given service has been gamified or not in the absence of knowledge about its production/consumption process.

Let us, for example, consider three, at first sight, virtually identical scenarios wherein a person plays a geocaching game (Geocaching 2013) in a public park. In the first scenario, the person is a geocaching enthusiast and one caching happens to lead him or her to the park. In this scenario, no gamification has occurred, since the core service is the geocaching game itself and the park is the enhancing service: a suitable location for the geocache. Here the geocaching service is a full-fledged game. In the second scenario, the city has set up a geocaching game for its residents, to encourage more active use of the 
Table 2 Core definitions of gamification broken down into elemental aspects

\begin{tabular}{|c|c|c|c|c|c|}
\hline Source & System elements/affordances & $\begin{array}{l}\text { Psychological mediators/ } \\
\text { outcomes }\end{array}$ & Goal of gamification & Context of gamification & $\begin{array}{l}\text { Focus of the } \\
\text { definitions }\end{array}$ \\
\hline $\begin{array}{l}\text { Deterding et al. } \\
\text { (2011) }\end{array}$ & $\begin{array}{l}\text { "game design elements" - } \\
\text { elements that are } \\
\text { characteristic of games }\end{array}$ & [Not explicated] & [Not explicated] & $\begin{array}{l}\text { "non-game contexts" - } \\
\text { Argumentation by the } \\
\text { authors: adding game } \\
\text { design in games is } \\
\text { paradoxical }\end{array}$ & System \\
\hline $\begin{array}{l}\text { Huotari and Hamari } \\
\text { (2012); Present } \\
\text { study }\end{array}$ & $\begin{array}{l}\text { "(motivational) affordances" - } \\
\text { not explicitly restricting } \\
\text { the set of design elements }\end{array}$ & $\begin{array}{l}\text { "gameful experiences" - } \\
\text { referring to, but not } \\
\text { limited to, the set } \\
\text { listed in Table } 1\end{array}$ & $\begin{array}{l}\text { "value creation"- } \\
\text { derived from } \\
\text { service marketing } \\
\text { literature with the } \\
\text { aim to refer to } \\
\text { whatever set of } \\
\text { activities that are } \\
\text { gamified }\end{array}$ & $\begin{array}{l}\text { [Not explicated] - } \\
\text { Argumentation by the } \\
\text { authors: it is impossible } \\
\text { to objectively distinguish } \\
\text { a game and a non-game } \\
\text { context since the experi- } \\
\text { ence of 'gamefulness' is } \\
\text { subjective and experiential }\end{array}$ & User experience \\
\hline
\end{tabular}

city's parks. In this case, gamification has occurred, because here the city parks represent the core service and the geocaching game the enhancing service. In the third scenario, a group of outdoor enthusiasts has implemented a geocaching game in the park in order to make trekking in an urban environment more gameful. Here again, gamification has occurred: the hikers have made their hobby (the core service) more gameful through geocaching (an enhancing service).

Therefore, if one is to identify gamification, it is essential to distinguish between the enhancing service providing affordances for gameful experiences and the core service that is being supported by that enhancing service and thus aiding the actor who is the gamifier. Table 3 gives examples of gamified services, making explicit the core and enhancing service in each case, and Table 4 distinguishes among various possible gamifying actors. In theory, it is the customer's subjective perception that determines what should be considered the core service; however, up to that point, it is the gamification provider's perception that is decisive, for it is the gamification provider who decides which service to gamify.

\section{Four possible gamification providers}

From the gamification design perspective, it is important to identify the individual actors and their respective roles in the gamification process. The geocaching scenarios presented above demonstrates that it is not always the provider of the core service that enhances the core service via gamification. In scenario 2, the gamification is provided by the city, possibly with the aid of a third party, whereas the trekkers themselves perform the gamification in scenario 3 . We have identified four possible gamification providers (i.e., providers of the enhancing service). These are 1) the core service provider, 2) a third-party service provider, 3 ) the customer him- or herself, and 4) another customer. The enhanced service is provided either by one of these four parties or by a combination of them. Table 4 presents examples of gamified services involving a range of gamification providers.

For service designers, it is important not only to recognize the various gamification providers but also to understand that third parties and customers may gamify a service independently of the core service provider (as with the third geocaching

Table 3 Examples of gamification

\begin{tabular}{llr}
\hline Core service & Enhancing service & Gamified service \\
\hline Profile in LinkedIn & $\begin{array}{c}\text { Progress bar for measuring progress in entry of } \\
\text { personal details } \\
\text { Mayorship competition in Foursquare }\end{array}$ & $\begin{array}{r}\text { The enhancing service increases the perceived value of filling in all } \\
\text { details by making use of progress-related psychological tendencies. } \\
\text { The enhancing service creates a competition between customers wherein } \\
\text { they have to visit the cafe frequently enough. This generates retention. }\end{array}$ \\
Dry cleaner's & $\begin{array}{l}\text { Loyalty card on which the customer receives } \\
\text { one stamp toward a benefit for every visit }\end{array}$ & $\begin{array}{c}\text { The enhancing service takes advantage of psychological tendencies } \\
\text { related to progress and thus increases the perceived value of using } \\
\text { the same dry cleaning service. }\end{array}$ \\
Gym & HeiaHeia or Fitocracy & $\begin{array}{c}\text { The physical training experience sets goals itself and assists in monitoring } \\
\text { the progress of the training. }\end{array}$ \\
\hline
\end{tabular}


Table 4 Examples of gamified services, from various gamification providers

\begin{tabular}{|c|c|c|c|}
\hline Core service & Enhancing service & Gamified service & Gamification provider \\
\hline Airline (e.g. Finnair) & $\begin{array}{l}\text { Mileage program involving levels that } \\
\text { can be attained by accumulating tier } \\
\text { points, award points and/or flights } \\
\text { (Finnair Plus in a Nutshell 2014) }\end{array}$ & $\begin{array}{l}\text { Customers who use the airline regularly } \\
\text { can reach higher membership levels } \\
\text { and get premium service. }\end{array}$ & Airline (the core service provider) \\
\hline Restaurant (e.g., Starbucks) & Local badges in Foursquare & $\begin{array}{l}\text { Customers who check in at least three } \\
\text { times a week at the same location } \\
\text { with Foursquare getting a badge }\end{array}$ & Foursquare (a third party) \\
\hline Sports bar & Drinking game (Yahoo Answers 2013) & $\begin{array}{l}\text { Deciding to incorporate a drinking } \\
\text { game into watching hockey, for } \\
\text { example }\end{array}$ & The customer him- or herself \\
\hline National Park & $\begin{array}{l}\text { Geocaching game (Outdoors.fi 2014; } \\
\text { Geocaching 2013) }\end{array}$ & $\begin{array}{l}\text { Adding a geocaching quests to a hike in } \\
\text { a national park. }\end{array}$ & $\begin{array}{l}\text { Other customers (through } \\
\text { Geocaching.com) }\end{array}$ \\
\hline
\end{tabular}

scenario and Foursquare's local badges in Table 4). Such cases may prove advantageous for the core service provider, and service designers may want to create opportunities for said customer or third-party initiative and even encourage it. For example, the application programming interfaces (APIs) that many companies offer software developers can be a way for a firm to let third parties gamify its service.

\section{Gamification as communicative staging of service environment}

Because the company's role in the value creation is to support customers' processes by offering resources for these, for the gamification designer it is interesting also to examine gamification from the angle of operand and operant resources. After all, these resources are the designer's tools in the gamification process.

A gamified service is, by our definition, a service package consisting of a core service and an enhancing service that supports gameful experiences. As we have pointed out in Section 5, the key resources in the creation of gameful experiences are operant resources. Therefore, we can see that the job of a gamification designer is mainly to use operand resources of the core service and combine the operant resources of the core service and of the enhancing service into a meaningful whole. This can be thought of as a gameful framing of the core service or, as more generally conceptualized in service marketing, communicative staging (Arnould 2007; Arnould et al. 1998). A concept used to denote how the service provider communicates its interpretation of the service environment, communicative staging refers to conveying experiential meanings from service provider to customer, and back, and between customers. Its efficiency relies on the mutuality of cultural understanding (Arnould 2007). A parallel term is "substantive staging"; this refers to the presentation of the physical service environment (Arnould et al. 1998), often denoted in the service literature as servicescape (Bitner 1992).
A clear connection can be seen also with service design methods drawing from the performing arts, wherein storyboarding is used both to visualize the customer as part of a physical setting and to position the customer along the narrative continuum (Miettinen and Koivisto 2009).

A good example of communicative staging is the gamification implemented at the Trader Joe's grocery store in Berkeley, California. To help parents with their grocery shopping, each day the workers hide a teddy bear somewhere in the store and challenge the children of their clientele to look for it. Those who find the bear are rewarded with some candy or a bag of nuts. This quest makes the store visit much more exciting for the children (by creating gameful experiences) and much less stressful for the parents (supporting the overall value creation of the store experience). The gamification is done purely by rendering new meanings for existing resources, such as the hidden teddy bear (the mission) and the treats (the reward).

Similarly, Foursquare's services, the LinkedIn progress bar, homespun drinking games, and the other examples in Table 4 are ultimately about giving and conveying new meanings to existing resources.

\section{Conclusion}

In game studies, games have been defined in terms of a set of necessary conditions. These conditions can be divided into systemic and experiential conditions. This approach is compatible with service marketing theory, which emphasizes customer's role as co-producer of the service and which can be used also for marketing of goods and products.

Game study literature and service marketing literature are largely complementary. However, the definition of gamification proposed by Deterding et al. (2011) adopts a systemic approach seemingly incompatible with the understanding of value creation in the service literature, which, in contrast, emphasizes the experiential and psychological nature of 
services. The definition by Werbach (2014) is closer to service marketing theory as it sees gamification as a process. However, it remains on such a general level that attempts to connect gamification to the service marketing literature remain vague and imprecise when using it. In contrast, we have attempted to tie gamification in with existing knowledge from service marketing, with concepts such as service package, value-inuse, and service systems. Then, we defined gamification from the perspective of service marketing, as "a process of enhancing a service with affordances for gameful experiences in order to support users' overall value creation." This definition emphasizes gamification's two, parallel goals: to afford gameful experiences and to support the customer's experienced value-in-use of the core service process. The proposed definition is agnostic with respect to the nature of the core service that is being gamified. In this, it challenges the view that gamification can only take place when game-like elements are used in non-gaming contexts.

Looking at gamification from this perspective also enables one to understand that it is not only a service designer who can employ gamification. Here, we have identified four possible gamification providers: the core service provider, a third-party service provider, the customer/user, and some other customer/ user. Furthermore, we have enriched the discussion of the complex nature of gamification as a service. Theoretical background from service marketing enabled us to identify in a seemingly obvious scene of gamification three distinct scenarios by considering multiple options as to the core service and also the party providing the gamification. Finally, we have also presented gamification as communicative staging of the service environment, which aids in understanding gamification as a way of conveying experiential meanings between service provider and customers.

We believe that anchoring gamification in the service marketing literature will assist in researchers' examination of how gamification can contribute to marketing sciences, in connecting gamification to overall business strategy and also in building a bridge between game studies and marketing literature.

One interesting avenue for future research might be the investigation of how gamification could be integrated into an expanded version of the servicescape model presented by Bitner in 1992, as Arnould et al. (1998) have suggested. Another interesting path could be to study the social aspects of gamification by considering social networks as operant resources. Foursquare, for instance, makes extensive use of its users' social networks when gamifying other services. The social networks of the users represent operant resources for Foursquare's users. More thorough analysis of the theme remains for further research. From the point of view of game studies, instead of merely investigating gamification's direct effect on behavioural outcomes, the theoretical framing adopted in this study enables further research to also take experiential aspects into account. On all fronts, it would be interesting to empirically investigate the psychological effect that mediate the effect between affordances and behaviour.

Acknowledgements We would like to thank the participants and organisers of CHI 2011 Gamification Workshop for the valuable feedback that we received concerning the early ideas presented in the early draft of this paper, as well as the organisers of the MindTrek Conference 2012. The research was supported by the following grants: TEKES/40111/14 and TEKES/40107/14 from Tekes - the Finnish Funding Agency for Innovation.

\section{References}

Alt, R., Abramowicz, W., \& Demirkan, H. (2010). Service-orientation in electronic markets. Electronic Markets, 20(3-4), 177-180.

Arnould, E. (2007). Consuming experience: Retrospects and prospects. In A. Carù, \& B. Cova (Eds.), Consuming experience (pp. 185-194). Oxon: Routledge.

Arnould, E. J., Price, L. L., \& Tierney, P. (1998). Communicative Staging of the Wilderness Servicescape. Service Industries Journal, 18(3), 90-115.

Avedon, E. M., \& Sutton-Smith, B. (1971). The study of games. New York: Wiley.

Bitner, M. J. (1992). Servicescapes: The impact of physical surroundings on customers and employees. Journal of Marketing, 56(2), 57-71.

Bittner, J. V., \& Shipper, J. (2014). Motivational effects and age differences of gamification in product advertising. Journal of Consumer Marketing, 31(5), 391-400.

Bonde, M. T., Makransky, G., Wandall, J., Larsen, M. V., Morsing, M., Jarmer, H., \& Sommer, M. O. A. (2014). Improving biotech education through gamified laboratory simulations. Nature Biotechnology, 32(7), 694-697.

Caillois, R. (1958). Man, play, and games. Glencoe, New York (1961 reprint).

Cechanowicz, J., Gutwin, C., Brownell, B., \& Goodfellow, L. (2013). Effects of gamification on participation and data quality in a realworld market research domain. In Proceedings of Gamification' 13, Stratford, Ontario, Canada, October 2-4, (pp. 58-65).

Christy, K. R., \& Fox, J. (2014). Leaderboards in a virtual classroom: a test of stereotype threat and social comparison explanations for women's math performance. Computers \& Education, 78, 66-77.

Cocosila, M., \& Archer, N. (2010). Adoption of mobile ict for health promotion: an empirical investigation. Electronic Markets, 20(3-4), 241-250.

Constantin, J. A., \& Lusch, R. F. (1994). Understanding resource management: How to deploy your people, products, and processes for maximum productivity. Planning Forum (August).

Crawford, C. (1982). The art of computer game design. http://www. vic20.vaxxine.com/wiki/images/9/96/Art_of_Game_Design.pdf. Accessed 13 Dec 2013.

Csíkszentmihályi, M. (1990). Flow: The psychology of optimal experience. New York: Harper \& Row.

Czarnecki, C., Winkelmann, A., \& Spiliopoulou, M. (2010). Servicess in electronic telecommunication markets: A framework for planning the virtualization of processes. Electronic Markets, 20(3-4), 197-207.

Dai, H., \& Salam, A. F. (2014). Does service convenience matter? An empirical assesment of service quality, service convenience and exchange relationship in electronic mediated environment. Electronic Markets, 24(4), 269-284. 
de-Marcos, L., Domínguez, A., Saenz-de-Navarrete, J., \& Pagés, C. (2014). An empirical study comparing gamification and social networking on e-learning. Computers \& Education, 75, 82-91.

Denny, P. (2013). The effect of virtual achievements on student engagement. In Proceedings of CHI 2013: Changing Perspectives, Paris, France, April 27-May 2, 2013, (pp. 763-772).

Deterding, S., Dixon, D., Khaled, R., \& Nacke, L. (2011). From game design elements to gamefulness: Defining "gamification." In Proceedings of the 15th International Academic MindTrek Conference: Envisioning Future Media Environments (pp. 9-15). New York: ACM.

Domínguez, A., Saenz-de-Navarrete, J., de-Marcos, L., Fernández-Sanz, L., Pagés, C., \& Martínez-Herráiz, J.-J. (2013). Gamifying learning experiences: practical implications and outcomes. Computers \& Education, 63, 380-392.

Farzan, R., \& Brusilovsky, P. (2011). Encouraging user participation in a course recommender system: an impact on user behavior. Computers in Human Behavior, 27(1), 276-284.

Filsecker, M., \& Hickey, D. T. (2014). A multilevel analysis of the effects of external rewards on elementary students' motivation, engagement and learning in an educational game. Computers \& Education, 75, 136-148.

Finnair Plus in a Nutshell (2014), http://www.finnair.com/FI/GB/finnairplus/what-is-finnair-plus. Accessed 8 Dec 2014.

Geocaching (2013). http://www.geocaching.com/. Accessed 13 Dec 2013.

Gibson, J. J. (1977). The theory of affordances. USA: Hilldale.

Greeno, J. M. (1994). Gibson's affordances. Psychological Review, 101(2), 336-342.

Grönroos, C. (1994). Quo vadis, marketing? Toward a relationship marketing paradigm. Journal of Marketing Management, 10(5), 347-360.

Grönroos, C. (2006). Adopting a service logic for marketing. Marketing Theory, 6(3), 317-333.

Grönroos, C. (2007). Service management and marketing: Customer management in service competition, 3rd ed., Wiley.

Hakulinen, L., Auvinen, T., \& Korhonen, A. (2013). Empirical study on the effect of achievement badges in TRAKLA2 online learning environment. In Proceedings of Learning and Teaching in Computing and Engineering (LaTiCE) conference, Macau, March 21-24, 2013, (pp. 47-54).

Hamari, J. (2013). Transforming homo economicus into homo ludens: A field experiment on gamification in a utilitarian peer-to-peer trading service. Electronic Commerce Research and Applications, 12(4), 236-245.

Hamari, J. (2015). Do badges increase user activity? A field experiment on effects of gamification. Computers in Human Behavior. doi: 10. 1016/j.chb.2015.03.036

Hamari, J., \& Järvinen, A. (2011). Building customer relationship through game mechanics in social games. In M. Cruz-Cunha, V. Carvalho, \& P. Tavares (Eds.), Business, technological and social dimensions of computer games: Multidisciplinary developments (pp. 348-365). Hershey: IGI Global.

Hamari, J., \& Koivisto, J. (2015). "Working out for likes": An empirical study on social influence in exercise gamification. Computers in Human Behavior, 50, 333-347.

Hamari, J., \& Lehdonvirta, V. (2010). Game design as marketing: how game mechanics create demand for virtual goods. International Journal of Business Science \& Applied Management, 5(1), 14-29.

Hamari, J., \& Tuunanen, J. (2014). Player types: A meta-synthesis. Transactions of the Digital Games Research Association, 1(2), 29-53.

Hamari, J., Koivisto, J., \& Pakkanen, T. (2014a). Do persuasive technologies persuade? - A review of empirical studies. In A. Spagnolli et al. (Eds.), Persuasive Technology, LNCS (vol. 8462, pp. 118-136). Springer International Publishing Switzerland.

Hamari, J., Koivisto, J., \& Sarsa, H. (2014b). Does gamification work? - A literature review of empirical studies on gamification. In Proceedings of the 47th Hawaii International Conference on System Sciences (pp. 6-9). Hawaii.

Hamari, J., Huotari, K., \& Tolvanen, J. (2015). Gamification from the economics perspective. In S. P. Walz, \& S. Deterding (Eds.), The Gameful World: Approaches, Issues, Applications (pp. 139-161). Cambridge: MIT Press.

Hense, J., Klevers, M., Sailer, M., Horenburg, T., Mandl, H., \& Günthner, W. (2014). Using gamification to enhance staff motivation in logistics. Lecture Notes in Computer Science (including subseries Lecture Notes in Artificial Intelligence and Lecture Notes in Bioinformatics), 8264, 206-213.

Huizinga, J. (1944). Homo ludens. Boston: Beacon Press (1950 reprint).

Huotari, K., \& Hamari, J. (2012). Defining gamification: a service marketing perspective. In Proceeding of the 16th International Academic MindTrek Conference (pp. 17-22). ACM.

Jones, B. A., Madden, G. J., \& Wengreen, H. J. (2014). The FIT game: Preliminary evaluation of a gamification approach to increasing fruit and vegetable consumption in school. Preventive Medicine, $68,76-79$.

Jung, J. H., Schneider, C., \& Valacich, J. (2010). Enhancing the motivational affordance of information systems: The effects of real-time performance feedback and goal setting in group collaboration environments. Management Science, 56(4), 724-742.

Juul, J. (2003). The game, the player, the world: Looking for a heart of gameness. In M. Copier, \& J. Raessens (Eds.), Level-up: digital games research conference proceedings (pp. 30-45). The Netherlands: Utrecht.

Kelley, D. (1988). The art of reasoning. New York: W. W. Norton \& Company.

Kim, A. J. (2008). Putting the fun in functional: applying game mechanics to functional software. http:/www.slideshare.net/amyjokim/puttingthe-fun-in-functiona?type=powerpoint. Accessed 13 Dec 2013.

Klemke, R., Kravcik, M., \& Bohuschke, F., (2014). Energy-efficient and safe driving using a situation-aware gamification approach in logistics. Lecture Notes in Computer Science (including subseries Lecture Notes in Artificial Intelligence and Lecture Notes in Bioinformatics) 8605, (pp. 3-15).

McGonigal, J. (2011). Reality is broken: Why games make us better and how they can change the world. Penguin Books.

Miettinen, S., \& Koivisto, M. (Eds.) (2009). Designing services with innovative methods. University of Art and Design Helsinki publication series, B 93/Kuopio Academy of Design's Taitemia publication series, 33. Keuruu: Otava.

Norman, D. A. (2002). The design of everyday things. New York: Basic Books.

Outdoors.fi (2014) Activities in Nuuksio National Park. http://www. outdoors.fi/nuuksionp/activities. Accessed 8 Dec 2014

Ryan, R., Rigby, C., \& Przybylski, A. (2006). The motivational pull of video games: A self-determination theory approach. Motivation and Emotion, 30(4), 344-360.

Salen, K., \& Zimmerman, E. (2004). Rules of play: Game design fundamentals. MIT Press.

Sigala, M. (2015). The application and impact of gamification funware on trip planning and experiences: the case of tripadvisor's funware. Electronic Markets, 1-21.

Simões, J., Díaz Redondo, R., \& Fernández Vilas, A. (2013). A social gamification framework for a K-6 learning platform. Computers in Human Behavior, 29(2), 345-353.

Spohrer, J., Vargo, S. L., Caswell, N., \& Maglio, P. P. (2008). The service system is the basic abstraction of service science. In Proceedings of the 41st Annual Hawaii International Conference on System Sciences (p. 104). IEEE.

Stenros, J., \& Sotamaa, O. (2009). Commoditization of helping players play: Rise of the service paradigm. In Breaking new ground: Innovation in games, play, practice and theory - Proceedings of DiGRA 2009. 
Suits, B. (1978). The grasshopper. Toronto: University of Toronto Press.

Takahashi, D. (2011). Game guru jane mcgonigal says "gamification" should make tasks hard, not easy. http://venturebeat.com/2011/01/ 20/game-guru-jane-mcgonigal-says-gamification-should-be-hardnot-easy/. Accessed 13 Dec 2013.

Terlutter, R., \& Capella, M. L. (2013). The gamification of advertising: analysis and research directions of in-game advertising, advergames, and advertising in social network games. Journal of Advertising, $42(2-3), 95-112$.

Terrill, B. (2008). My coverage of lobby [sic] of the social gaming summit. http://www.bretterrill.com/2008/06/my-coverage-of-lobby-ofsocial-gaming.html. Accessed 13 Dec 2013.

Vargo, S. L., \& Lusch, R. F. (2004). Evolving to a new dominant logic for marketing. Journal of Marketing, 68(1), 1-17.

Vargo, S., \& Lusch, R. (2008). Service-dominant logic: Continuing the evolution. Journal of the Academy of Marketing Science, 36(1), 1-10.
Vargo, S. L., Lusch, R. F., Akaka, M. A., \& He, Y. (2010). servicedominant logic: A review and assessment. Review of Marketing Research, 6, 125-167.

Werbach, K. (2014). (Re) Defining Gamification: A Process Approach. In Persuasive Technology (pp. 266-272). Springer International Publishing.

Yahoo Answers (2013). Drinking game to play while watching hockey? http://answers.yahoo.com/question/index?qid= 20091204114828AAsXR91. Accessed 13 Dec 2013.

Yee, N. (2006). Motivations for play in online games. Journal of CyberPsychology \& Behavior, 9(6), 772-775.

Zhang, P. (2008). Motivational affordances: Reasons for ICT design and use (Technical Opinion). Communications of the ACM, 51(11), 145-147. 